\title{
A IDEIA DE JUSTIÇA E O PENTECOSTALISMO ASSEMBLEIANO NO BRASIL
}

\author{
THE IDEA OF JUSTICE AND ASSEMBLEIAN PENTECOSTALISM IN BRAZIL
}

James Washington 1

\begin{abstract}
Resumo: Este artigo busca trabalhar de maneria teórica o conceito de justiça em John Rawls e Charles Taylor, entendendo este conceito, dentro da observância aos príncipios liberais da liberdade, igualdade e pluralidade. Diante disso, elencamos questões como consenso sobreposto, véu de ignorância e reconhecimento, como categorias chave para a nossa análise. Este tema guarda em si mesmo uma importância nos debates sobre o funcionamento da democracia contemporânea, sem deixar de lado as implicações empíricas, trazendo com isso reflexões sobre a realidade brasileira. $\mathrm{O}$ caso brasileiro é apresentado com vista ao papel das igrejas pentecostais neste processo democrático liberal, em especial, colocamos o papel das Assembleias de Deus, bem como a luta travada entre as perpectivas religiosas e laicistas no mesmo cenário brasileiro.
\end{abstract}

Palavras-chave: liberalismo; direitos; religião

\begin{abstract}
This article seeks to theoretically work the concept of justice in John Rawls and Charles Taylor, understanding this concept, within the observance of the liberal principles of freedom, equality and plurality. Given this, we list issues such as overlapping consensus, veil of ignorance and recognition as key categories for our analysis. This theme holds in itself an importance in the debates on the functioning of contemporary democracy, without neglecting its empirical implications, bringing with it reflections on the Brazilian reality. The Brazilian case is presented with a view to the role of the Pentecostal churches in this liberal democratic process. In particular, we put the role of the Assemblies of God, as well as the struggle waged between religious and secular perspectives in the same Brazilian scenario.
\end{abstract}

Keywords: liberalism; rights; religion

\section{Introdução}

O liberalismo político se notabilizou por ser um modelo político que imprimiu, após a derrocada do regime feudal, uma ideologia que tem como ponto central o respeito aos chamados direitos fundamentais. Estes direitos são colocados como naturais e são representados pela liberdade, igualdade perante a lei e a propriedade. Estes mesmos temas foram motivo para as discussões clássicas do liberalismo, envolvendo teóricos de diferentes orientações como Thomas Hobbes, John Locke, Jean-Jaques Rousseau.

1 Professor de Sociologia do Instituto Federal - AL, doutorando em Ciências Sociais (UNESP), james.was@hotmail.com 
Contudo, o debate sobre estes temas seguiu até o séc. XX e foi ascrescido de uma problemática que aconpanha a emergência dos direitos sociais (MARSHALL, 2002), a saber: o tema da pluralidade cultural e do reconhecimento. Acompanhando este movimento, temos teóricos liberais contemporâneos como John Rawls e Chales Taylor. Contudo, esta nova temática não ficou restrita ao âmbito da política institucional e da sociedade, mas moveu e move uma série de debates que envolvem os segmentos religiosos em choque direto com movimentos laicistas, propriamente no contexto brasileiro.

Neste sentido, colocamos como exemplo desta problemática as igrejas Assembleias de Deus no Brasil. Estas, por sua vez, se pautam em um posicionamento que vai da vitimização (ALENCAR, 2011), até a imposição gradativa de uma projeto político interno conservador e pautado por príncipios religiosos. O Brasil é então caraterizado como um espaço social de lutas dentro do campo religioso, que envolve os defensores do laicismo e dos direitos sociais e os segmentos religiosos pentecostais, defensores da interpretação biblicista (em especial os assembleianos). Porém, há que se lembrar, que a posição assembleiana também é fruto de convergências entorno de temas comuns a outras denominações, como a defesa da abertura a liberdade religiosa, recurso imprescindível para o empreendimento de um proselitismo cada vez mais abrangente.

A questão fundamental é quanto às possibilidades de diálogo que possam existir e por que a liberdade e a igualdade são elementos que podem nos ajudar a entendermos as dinâmicas sociorreligiosas modernas e também atuais, dentro dos contextos ocidental e brasileiro.

\section{0 dilema do liberalismo: liberdade, igualdade e pluralidade.}

Uma das teorias que mais ganharam corpo dentro da Ciência Política e da Economia desde o século XVII foi o Liberalismo. Em suma, se refere, dentre outras coisas, à possibilidade ampliada de liberdade, igualdade perante a lei e iniciativa individual de cada membro da sociedade, criando possibilidades que podem inferir em ganhos, como meio próprio de subsistência. Desta forma, seriam extremamente preciosos os elementos motores que constituem tal ato: a própria vida e a propriedade adquirida, os bens (LOCKE, 2006).

O cerne desta teoria está no direito à propriedade, adquirida por meio do trabalho, gerando uma salvaguarda feita por meio de um Estado Constitucional2, que serviria como

\footnotetext{
2 Na Inglaterrra, berço da formação do Liberalismo Político e Econômico, a divisão parlamentarista obedece a subdivisão: Câmara dos Lords (nomeada pela realiza); Câmara dos Comuns (eleita pelo povo) e o poder Real Último Andar, n. 34, 2019
} 
guardião do direito individual inalienável (por isso, funtamenta-se em um jusnaturalismo). Isso designara um formato social moderno, em que o foco econômico do trabalho livre e do livre mercado se mesclam a uma realidade cujas oportunidades e recursos são escassos (SCHUMPETER, 2017). Ao mesmo tempo, a disponibilidade destes recursos é entrelaçada por diferentes condicionamentos sociais (condição familiar, formação pessoal, habilidades e oportunidades), o que provoca um limiar de desigualdades que separam ou aproximam as pessoas da condição de adquirirem os bens de propriedade pessoal (WELFORT, 2006).

A "mágica simbólica" operada pelo liberalismo é promover a formação de uma estrutura que se reproduz, afirmando que todos teriam possibilidades de aquisição de uma "vida boa", por meio do livre curso de suas vontades, desconsiderando que diante de tal largada, as pessoas partem para as suas conquistas em diferentes pontos, umas mais à frente do que outras (EHRENBERG, 2010). Apesar disso, os condicionantes citados tendem a sofrer alterações em conformidade com as oportunidades que vão sendo conquistadas por diferentes pessoas em diferentes posições sociais, gerando o efeito perverso de retroalimentarem a falácia simbólica da igualdade de condições, colocando por exemplo, a formação de capital cultural, como estratégica simples e básica para tal empreitada (BOURDIEU; PASSERON, 2011).

Os efeitos diretos desta liberdade se fizeram sentir dentro dos pressupostos religiosos do anglicanismo inglês e também do calvinismo francês/holandês. O modelo clássico do catolicismo com sua ascese extramundana, perdera o sentido, enquanto fuga do mundo e busca pela contemplação, dando lugar a uma ascese intramundana de ocupação dos espaços sociais por meio do trabalho. O sentido das ações agora, volta-se para o agir no mundo, de forma a honrar a Deus, por meio das atividades laborais, criando e fortalecendo, economicamente, o meio em que se vive (WEBER, 2004).

Entre decisões políticas de rompimento com antigos dogmas e doutrinas e novas formas de ação laboral dentro da religião, prevalece um sentimento de que ao ser humano, fora designada a tarefa de exercer a liderança política do mundo, como o fizera Adão (isso justificado através da teoria do direito divino), como mostrara WELFORT (2006). Mas esta liberdade de trabalhar e de governar está "amarrada" ao símbolo e figura de Deus em dois sentidos: por meio do livre arbítrio arminiano, enquanto sinal de responsabilidade sobre os próprios atos (por isso institui-se a Bíblia enquanto regra literal de fé); e por meio da soberania divina calvinista, que em outro sentido, designava a Deus a predestinação de quem

(reivindicador da ideia de direito divino). Este último até hoje age como árbitro das controvérsias entre as duas câmaras. 
seria ou não salvo, garantindo ao escolhido uma garantia de salvação por meio da chamada "preservação dos santos"3.

Desta forma, a liberdade toma em sentido moderno dois caminhos paralelos: um que a coloca enquanto elemento básico do liberalismo político e econômico, tendo no Estado uma figura de regulação; e outro que coloca a interpretação religiosa da liberdade de ação ora sob ética da responsabilidade (Arminiana), ora sob a ética da convicção (Calvinista), ambas dividindo opiniões dentro do cristianismo (WEBER, 2011). No campo político, no que se refere aos Estados Nacionais modernos, as imbricações entre estas duas perspectivas (político/econômica e religiosa), estão, ainda hoje, na cena dos debates sobre qual a equidistância ideal entre as intensões religiosas e o papel do Estado.

Neste debate, cabe salientar a importância da critica iluminista à ideia de racionalidade e independência do Estado. Entre os autores mais destacados está KANT (2015), que se esforça por tentar conciliar a questão dos direitos e da liberdade humana (enquanto pressuposto básico do liberalismo), ao bem estar comunitário. Esta operação é feita por um elemento ético de base cristã, chamado, "imperativo categórico", que em resumo admite que não se faz aos outros aquilo que não gostaria que se fizesse a si mesmo.

Foi seguindo este ideal, que a perspectiva egocêntrica da liberdade, alinhada à ideia de "bom", alicerce do estado de guerra na teoria contratualista, deu lugar há uma proposta inspirada pela ideia de "bem", formando assim um escopo filosófico que reage ao essencialismo e ao utilitarismo. A busca por este ideal de "bem", desde a Filosofia Antiga, mexeu com o imáginário de filósofos e entusiastas da política, entre eles, ARISTÓTELES (2009), para quem o termo "bem comum", se referia às pessoas do gênero masculino, gregos de nascença e que por sua vez, detinham direitos políticos e eram encarados por isso, como cidadãos. Neste quesito, o termo bem, inspirado na teoria kantiana, acabou por gerar uma nova perspectiva filosófica, conhecida de maneira geral como neocontratualismo, uma nova forma de ver o bem e a liberdade, agora como elemento inseparável das questões da igualdade e da pluralidade.

A igualdade aqui é encarada como um aspecto do mundo moderno e tem relação direta como o reconhecimento por parte do Estado (neste caso, o exemplo mais típico é o modelo inglês), dos direitos fundamentais já mencionados: da liberdade, igualdade e propriedade. Mas

\footnotetext{
3 Para os discípulos de Calvino, sua contribuição teológica se resumiria em cinco importantes assertivas: o mundo está envolto em uma depravação total; Deus escolhe quem irá resgatar por meio de uma salvação incondicional; a obra expiatória de Cristo tem alcance limitado pois nem todos a acolhem; existe uma graça irresistível que se apodera dos que forem escolhidos e Deus lhes garantiria a sua própria preservação eterna (PIPER, 2018).
} 
quanto ao aspecto da liberdade, quais seriam os avanços? Em termos práticos esta é a parte mais delicada da questão. O próprio governo inglês separava as pessoas livres, política e espiritualmente, daquelas que estavam sob a condição de julgo, perante os homens e perante seus débitos para com a religião. Neste aspecto, o liberalismo sempre colocou para "debaixo do tapete" a evidência de que a liberdade só poderia existir na lei, em meio a processos de reconhecimento e democratização das nações, convivendo, com regimes de execeção, ratificados por grupos econômicos, políticos e religiosos. Na prática, nem todos reconhecem os aspectos de liberdade e o enquadramento mais evidente é a simplicação das pessoas pelos termos: consumidor; cidadão e fiel (este último, contabilizando pela expressão: ganhar almas).

Neste sentido, a igualdade econômica restringe as pessoas a consumidores; a igualdade politica a cidadãos; a igualdade cultural religiosa a irmãos na fé. Em sequência temos a liberdade de ter e de viver, regulados por uma "segurança jurídica"; e de crer, regulado por uma "segurança eclesial", que afirma a dispensação de recompensas na forma de bens de salvação4. Por isso, não é de se estranhar que nações como a Inglaterra e os Estados Unidos, mesmo que imbuídas de um fervor liberal, tenham admitido em seu meio formas de xenofobia e colonização que permitiram a desiqualdade brutal de condições, baseada em justificativas raciais e de controle dos ímpetos, quando, na verdade, se tratava da criação e controle de mercados (SAHLINS, 1990). Há então uma separação entre modelos de igualdade e de liberdade? Esta é nossa tese preliminar aqui. Haveriam também diferentes modelos de igualdade de condições, correspondendo a estratégias políticas específicas? Esta é outra tese que vamos aos poucos apontanto em nosso horizonte teórico.

\section{A ideia de Justiça em John Rawls e Chales Taylor}

O ponto principal desta análise, contudo, recai sobre a ideia de bem, como algo ligado às ideias de liberdade e igualdade. Inspirado nos pressupostos Kantianos e contratualistas5, RAWLS (2016), vai estabelecer entre estes dois elementos uma correlação inalienável, ou seja: não pode haver igualdade sem que haja liberdade. Contudo, isso parece simples e de maneira direta resume o problema que foi a grande contradição do modelo contratual em

\footnotetext{
4 Os bens de salvação indicam aqui as ofertas religiosas ligadas a recompensas pós-morte. Entre as mais proeminentes estão: a ideia de um corpo glorioso e a vida terna com Deus. Como acesso a tal recompensa, são elaborados as mais diversas interpetações quanto aos ideais de obediência e fidelidade religiosas (SWEDBERG, 2005).

$5 \mathrm{O}$ contratualismo é um teoria que leva em conta a necessidade do estabelecimento de um acordo tácito entre as pessoas, para o fundação de um meio político regulador das condutas e da convivência social. Este elemento seria o Estado Moderno, que de acordo com o autor considerado, muda de estruturação.
} 
Hobbes, Locke e Rousseu. Porém, a questão levantada por meio de suas reflexões, visa resolver uma questão em especial: como estabelecer parâmetros de igualdade e de liberdade em meio a uma sociedade que agora nos séculos XX e XXI, se evidencia por meio de um pluralismo e uma cobrança por reconhecimento (de raça, crença, posicionamento político, modos de vida e de conhecimento).

O Contratualismo Clássico e o Neo-contratualismo:

\begin{tabular}{|c|c|c|}
\hline \multicolumn{3}{|c|}{ Contratualismo Clássico - Problema fundamental: o estado de guerra. } \\
\hline Hobbes & Locke & Rousseau \\
\hline $\begin{array}{l}\text { O estado de guerra enquanto } \\
\text { possibilidade de exercício } \\
\text { pleno da liberdade e } \\
\text { eminência de conflito. }\end{array}$ & $\begin{array}{l}\text { O estado de guerra enquanto } \\
\text { disputa pelos recursos } \\
\text { escassos. }\end{array}$ & $\begin{array}{l}\text { A diferença entre a pureza da } \\
\text { vida na natureza e o egoísmo } \\
\text { da vida em meio a sociedade. }\end{array}$ \\
\hline \multicolumn{3}{|c|}{ Contratualismo Clássico - A resolução do problema fundamental } \\
\hline $\begin{array}{l}\text { Constituição de um governo } \\
\text { monárquico centralizador. }\end{array}$ & $\begin{array}{l}\text { Constituição de um governo } \\
\text { parlamentarista, dissolvido } \\
\text { em câmaras representativas. }\end{array}$ & $\begin{array}{l}\text { Constituição de um modelo } \\
\text { de democracia onde a } \\
\text { escolha é dada pela maioria } \\
\text { em sufrágio universal. }\end{array}$ \\
\hline \multicolumn{3}{|c|}{ Neo-contratualismo - Problemas fundamentais: igualdade, liberdade e plurarilidade. } \\
\hline \multicolumn{3}{|c|}{ John Rawls } \\
\hline $\begin{array}{l}\text { A igualdade é encarada como } \\
\text { princípio constitucional de } \\
\text { defesa da vida e da } \\
\text { propriedade e não como fruto } \\
\text { de condicionantes sociais e } \\
\text { naturais (habilidades). }\end{array}$ & $\begin{array}{l}\text { A liberdade seria condição } \\
\text { essencial para a igualdade } \\
\text { constitucional, no sentido do } \\
\text { exercício de direitos. }\end{array}$ & $\begin{array}{l}\text { A pluralidade é o respeito as } \\
\text { diferentes formas de vida e } \\
\text { vivência experienciados. }\end{array}$ \\
\hline \multicolumn{3}{|c|}{ Neo-contratualismo - A resolução do problema fundamental } \\
\hline $\begin{array}{l}\text { Há uma concepção pública } \\
\text { de justiça que deve ser aceita } \\
\text { de maneira geral. }\end{array}$ & $\begin{array}{l}\text { Parte do princípio kantiano } \\
\text { de uma moralidade e um } \\
\text { respeito ao exercício ético } \\
\text { dos direitos fundamentais. }\end{array}$ & $\begin{array}{l}\text { Institui de forma hipotética a } \\
\text { ideia de um véu de } \\
\text { ignorância que pressupõe um } \\
\text { contrato sem a observância } \\
\text { das diferenças existentes. }\end{array}$ \\
\hline
\end{tabular}

Fonte: RAWLS, 2016.

Foi seguindo a teorização do contrato social (não mais com o intuito de acabar com um estado de guerra presente da sociedade, mas estabelecer formas de convívio diante das diferenças) que John Rawls (2016), tece a sua ideia de sociedade bem ordenada. Para isso, o conjunto de uma dada sociedade deveria: estar regido por uma concepção pública de justiça, onde todos aceitam os príncipios de igualdade e liberdade perante a observância da lei (não só as pessoas, mas também as instituições respeitariam estes príncipios, incluo aqui as instituições religosas em destaque); as pessoas são encaradas como morais, no sentido de cientes das regras que os cercam e se reconhecem como iguais na medida de serem todos, 
detentores dos mesmos direitos; são também livres, na medida em que podem intervir nas instituições, tendo como base os seus interesses e o respeito às regras.

\begin{abstract}
Pode-se salientar, porém, que, uma vez que os princípios de justiça são considerados decorrentes de um pacto original em uma situação de igualdade, não há como saber se o princípio da utilidade seria reconhecido. A princípio, seria pouco provável que pessoas que se considerassem iguais, com direito a fazer suas exigências umas as outras, aceitassem um princípio que talvez exija perspectivas de vidas inferiores para alguns simplesmente em troca de uma soma maior de vantagens desfrutadas por outros. Como todos querem proteger seus próprios interesses e suas capacidades de promover a própria concepção de bem, ninguém tem motivo para aceitar uma perda duradoura para si mesmo a fim de gerar um saldo líquido maior de satisfação (FROSI, 2014).
\end{abstract}

Aqui reside o enigma do contrato em RAWLS, o que faz com que sua teoria se apresente como algo tão hipotético, quanto à teoria clássica contratualista. Nesta última, o contrato é algo que fora instituído "em algum momento", sem precisarmos exatamente qual foi historicamente, com intuito de resolver o problema do estado de guerra e por consequência, do egoísmo humano que imperava nas relações sociais. RAWLS, a sua maneira, apela para uma série de condições prévias para que a sua forma de contrato social surta os seus efeitos. Em termos práticos, se fossemos comparar com a realidade história, relacionada as religiões protestantes históricas e pentecostais, por exemplo, os pressupostos de RAWLS soam como bons conselhos dos quais a realidade empírica se encontra em um triste distanciamento.

Apesar de Luteranos (1517); Anglicanos (1534); Presbiterianos (1560); Batistas (1612); Pietistas (1784); Metodistas (1787) e Holinnes (1890) se alinharem em torno de uma moralidade cristã, seu tratamento geral em relação a compreenção da igualdade sofre a interferência de seus próprios pressupostos religiosos. O que queremos dizer com isso? A igualdade aqui deve ser trabalhada em diferentes níveis, assim como a liberdade. Enquanto detendores de direitos, estas correntes religiosas defendem a manutenção da defesa da vida e da propriedade (acrescentaria a questão ao direito de crença e culto), como pontos em que todas as pessoas estariam em pé de igualdade. Contudo, no que se refere às questões ligadas aos pressupostos religiosos, nem todos são iguais. O meio social se divide entre os que aceitaram a fé teísta protestante e os que não a aceitaram. Isso rompe com o pressuposto da igualdade em termos culturais e lança diante das relações sociais uma diferença comumente chamada de julgo desigual6.

\footnotetext{
${ }_{6} \mathrm{O}$ julgo desigual é uma ideia tirada do contexto religioso pentecostal, que ilustra a forma como as alianças em torno do amor e do casamento foram compostas em períodos anteriores. Consiste na afirmação baseada no texto Último Andar, n. 34, 2019
} 
Este mesmo julgo desigual buscou por meio de formas culturais religiosas definir até mesmos as formas de casamento entre iguais na fé, com o intuito de evitar transtornos em relação às doutrinações diferentes. Portanto, não estamos apenas nos referenciando em diferenças ditadas por regimentos internos de instituições religiosas das mais variadas, mas em um conjunto prático de formas de ação de ditam diferenças comportamentais, estabelecendo formas de desigualdade.

Diante desta relação: liberdade, igualdade e pluralismo, RALWS propõe a resolução deste problema mediante a formulação do mais hipotético elemento de sua teoria: o véu de ignorância. Este referido véu nada mais é do que o pressuposto de que, conhecendo os indivíduos os seus direitos e liberdades dentro da sociedade, bem como, seu status social, habilidades naturais e talentos especializados, estes por sua vez não seriam levados em conta diante dos contatos culturais e não deviam estabelecer parâmetros de diferenciação.

Nisso reside a concepção de justiça de RAWLS, levando-se em conta que o referido véu da ignorância resulta na consideração das pessoas enquanto indivíduos morais. $\mathrm{O}$ problema é que também a moralidade, em um modelo de sociedade pluralizado por vários pressupostos e crenças, não é algo uniforme. Os modelos religiosos pressupõem, por exemplo, aspectos próprios, inspirados em interpretações literais da Bíblia, diferindo de um moral laica, exterior aos templos e presente na vida política e pública das pessoas (MONTERO, 2015). Como conciliar então, estas disparidades, diante da questão das diferenças e das contingências sociais, fruto da distribuição desigual das aptidões naturais e dos modos de vida (RAWLS, 2016).

Tentando contornar tal situação RAWLS propõe a existência de dois princípios reguladores de sua ideia de justiça: no primeiro teríamos o elenco das liberdades básicas sendo ampliadas a todos cidadãos indistintamente (como a liberdade de religião e expressão); posteriormente teríamos a distribuição igualitária de riquezas, permitindo que as disparidades sociais e econômicas beneficiem os membros menos favorecidos da sociedade na tentativa de equilibrar as diferenças. Neste ponto, o que garantiria que no jogo de forças, as pessoas aceitariam ter suas capacidades pessoais e habilidades, suprimidas mediante a proposta de equalização com os demais? A hipótese seria de que o tratamento desigual, mediante pessoas que vivem realidades desiguais, seria a tônica da busca pela superação das diferenças mediante o arbitrário de um novo contrato social. Este seria baseado em um consenso sobreposto, formado pelas opiniões individuais em uma dada sociedade.

da Segunda Carta aos Coríntios (6:14), de que uniões entre pessoas cristãs e não cristãs acarretam em desigualdades em termos de obediência a preceitos morais, possibilitando o surgimento de sérias divergências.

Último Andar, n. 34, 2019 
Outro autor que com propriedade vai trabalhar as questões relativas à justiça em ambientes plurais, será Charles TAYLOR. Em uma conferência dada na Universidade de Princeton em 1990, TAYLOR trabalha o tema da Política de Reconhecimento. "Nesta exposição sua primeira constatação é a de que mediante o regime das democracias liberais, o termo 'reconhecimento' se mostrou como expressão de direitos de minorias (religiosas, políticas e raciais), dentro de uma gramática dos conflitos políticos” (CARNEIRO, 2015, p. 178).

O reconhecimento seria uma base fundamental para o desenvolvimento da teoria da justiça em TAYLOR, visto que este não se trata de um mera formalidade social, pois é antes disso, uma necessidade humana, uma disposição em ver no outro não apenas um elemento portador de direitos uniformes, mas de um particularidade singular (TAYLOR, 1994). A gênese social da emergencia desta "corrida" pelo reconhecimento está embassada de um lado, "pela crise da posições hierarquicamente organizadas e de outro pela crise da ideia do progresso e da unidade, como pontos determinantes de um ilusminismo que fracassou, diante de sua crença irrefutável na racionalidade moderna" (CARNEIRO, 2015, p. 179).

Criticando a questão da formalidade democrática liberal e sua defesa inconteste ao jusnaturalismo, Taylor vai colocar em cena a crítica de dois autores clássicos da política e da Filosofia: Rousseau e Kant (CARNEIRO, 2015), evocando de um lado os seus esforços precurssores no debate sobre a relação: direitos, liberdade, diferenças e evidenciando limitações quanto ao equacionamento entre direitos fundamentais e liberdades individuais (TAYLOR, 1994).

Os precurssores do debate democrático moderno

\begin{tabular}{|c|c|}
\hline \multicolumn{2}{|c|}{ Rousseau / Kant - Diferenças dentro dos espectros democráticos. } \\
\hline Rousseau & Kant \\
\hline $\begin{array}{l}\text { Apresenta-nos a necessidade de } \\
\text { reconhecimento individual por parte de outros } \\
\text { pares sociais. Atrela a validade dos } \\
\text { pressupostos democráticos a uma vontade de } \\
\text { maioria que promove, em termos médios, } \\
\text { uma tentativa de homogeneização que não } \\
\text { colabora com o respeito a pluralidade. }\end{array}$ & $\begin{array}{l}\text { Por meio do pressuposto do imperativo } \\
\text { categórico, avança em termos da configuração } \\
\text { de um homem moral médio, que tem em sua } \\
\text { consciência o respeito aos direitos de outrem, } \\
\text { mas com a ressalva de também formatar de } \\
\text { maneira geral uma validade universal para este } \\
\text { caráter, sem condiderar as disparidades sociais. }\end{array}$ \\
\hline \multicolumn{2}{|c|}{ Espectros democráticos - A resolução do problema fundamental } \\
\hline $\begin{array}{l}\text { Vinculação da democracia há uma defesa } \\
\text { inconteste aos direitos universais e } \\
\text { uniformemente resguardados. }\end{array}$ & $\begin{array}{l}\text { Ideia de uma força moral que efetuaria nas } \\
\text { pessoas um obrigatoriedade de força } \\
\text { constrangedora. }\end{array}$ \\
\hline
\end{tabular}

Fonte: CARNEIRO, 2015, p. 182-184.

TAYLOR não concorda com o que ele próprio chama de método procedimental, dentro das análises democráticas modernas, preferindo construir formas de reconhecimento Último Andar, n. 34, 2019 
mais profundas dentro dos pressupostos democráticos. Nisso os dilemas levantados em Rousseau e Kant esbarram, no caso do primeiro, em uma necessidade de reconhecimento alheio, que prende as pessoas as questões as quais não podem controlar. Além disso, a confiança nos desejos da maioria, torna a média das opiniões algo sagrado, para além dos efeitos nocivos que podem acarretar no direito das minorias.

Já em Kant, não vemos aberto um espaço a diferença, colocando uma ideia de bem e um imperativo categórico que faz menção há um comportamento universal e não uma busca por reconhecimento particularizado. Esta situação por sinal, implica diretamente numa mudança de sentido quanto a validade da política do reconhecimento. Não é apenas a sua identificação, em um dado grupo ou pessoa que aquirique em TAYLOR a sua importância política. O seu não reconhecimento implica, ainda mais, em uma posição de rejeição e abandono de novas possibilidades de ser e de viver. Neste sentido, prevalecem as teorias de colocam a vontade geral e a uniformidade dos direitos como pressupostos democráticos (TAYLOR, 1994).

Portanto, seu modelo de justiça e liberdade tem como pressupostos um modelo de governo que não haja como elemento homogeneizante da sociedade, imprimindo pressupostos de uma só nação e de um só povo, quanto na verdade este mesmo povo é composto por diversas formas culturais e sociais que se formam em carater plural.

Contra este argumento meramente procedimental, o modelo de Estado em Taylor é
aquele que não abre mão de definir o que vê como "vida boa" em termos públicos,
abrindo por sua vez, espaços para a existência de modelos de vida diferenciados e
que não compartilham das difinições públicas de bem, mantendo assim os direitos
de liberdade, expressão e vivência. Para Taylor, tensões ou divergências acerca do
que seriam direitos canônicos ou restrições legítimas ao arbítrio individual seriam
inevitáveis neste processo e deveriam ser resolvidos através do próprio autogoverno
coletivo dos cidadãos. No entanto, essas tensões não seriam maiores do que as já
enfrentadas nas sociedades atuais, como as tensões entre liberdade e igualdade ou
prosperidade e justiça. Taylor apela então para os princípios da neutralidade e da
liberdade individual. Isto poderia abrir margem para o reconhecimento das
pluralidades, mas em termos práticos, parece apenas ser algo formal e não real
(CARNEIRO, 2015).

O curioso é que as ideias de neutralidade e liberdade surgem dentro de um pressuposto de tentantiva de igualdade e respeito a divergência no meio ocidental. No meio religioso, age como desafio ao rompimento entre igrejas (mais propriamente a católica e a protestante), que se deparam, por sua vez, com demandas de grupos seculares, havendo em ambos os lados (religiosos e seculares), uma dificuldade quanto ao reconhecimento mútuo das demandas.

É problemático evocar a teoria de Taylor nestes casos em que a neutralidade e a liberdade dão lugar a um pressoposto de defesa da fé que não apenas nega a possibilidade da 
pluralidade, como também busca homogeneizar as diferenças por meio da conversão religiosa. Haja vista que esta mesma conversão não garante de todo, a mudança cultutal, mas acaba por promover embates sobre a legitimidade da imposição de uma verdade de fé, enquanto verdade universal.

\section{A dificuldade assembleiana em lidar com a liberdade, a igualdade e a pluralidade.}

Feita uma breve exposição sobre a teoria da Justiça em dois autores basilares deste campo teórico (Rawls e Taylor), vamos agora problematizar as suas assertivas em relação ao comportamento individual e coletivo de uma instituição religiosa brasileira: as Assembleias de Deus. Devemos, neste caso, antes de tudo, salientar duas coisas: a primeira delas é que entendemos por Assembleias de Deus um imenso "guarda chuva denominacional", que apesar de plural em alguns detalhes doutrinários e de usos e costumes, guarda em si pressupostos de um modelo religioso pentecostal, de raiz sueco/nordestina (ALENCAR, 2012), que se notabiliza, em termos gerais, por seu proselitismo e por seu sectarismo acentuado. Isso já nos coloca diante da questão de que a escolha desta igreja, como exemplificação, se dá pelo fato de que tanto o seu proselitismo como o seu sectarismo, terem aberto caminho para uma política denominacional mais conservadora em relação às liberdades individuais e direitos de minorias sociais. 7

A segunda questão fica por conta de que sua rejeição à pluralidade, fato que pode ser evocado contra si mesmo, na medida em que guarda em seu próprio meio uma gama de instituições religiosas que usam a marca "Assembleia de Deus" e são consideradas como “igrejas irmãs"s. Esta é uma forma de camuflar as divergências políticas internas, geradoras de rupturas institucionais e mais que isso, negar a possibilidade de uma pluralidade de interpretações dentro de um mesmo texto referêncial (a Bíblia). Somado a isso ainda temos uma rejeição (deliberada e protecionista) de cúpula, quanto aos contatos culturais e às liberdades individuais, ao mesmo tempo em que se tem um ecumenismo de base, dificil de ser

\footnotetext{
${ }^{7}$ Seu modelo de defesa da liberdade religiosa (enquanto pensamento e crença), se indentifica com os argumentos das igrejas protestantes históricas e neopentecostais, mas guarda uma ressalva quanto se refere posicionamento politico partidário. Este último fora usado a partir da década de $1980 \mathrm{em}$ diante, como plataforma para a proteção dos interesses do mercado religoso assembleiano e sua expansão, mas também como forma de contenção de direitos considerados nocivos à seara religiosa, como a questão da defesa de modelos alternativos de família; do aborto e das questões ligadas à homofobia. Já as igrejas neopentecostais (Universal do Reino de Deus; Mundial do Poder de Deus; Internacional da Graça, entre outras.), aproveitaram este espaço a sua maneira, focando menos nos embates polêmicos e mais nas conceções midiáticas para fortalecimento e divulgação de seus bens de salvação e a criação de uma guerra necessária, de cunho espiritual.

8 Isso em parte explica o seu crescimento, que mescla: subdivisão de poderes locais, regionais e nacionais, sob a justificativa simbólica do chamado vocacional.
} 
censurado e que promove contatos denominacionais e seculares a todo o tempo (MARIZ, 2001).

Como pano de fundo, temos ainda que lembrar que o debate liberal brasileiro, ligado a um modelo de desenvolvimento próprio (de modernização tardia), tem como marca os antigos laços do clientelismo e de um patriarcado conservador, mesclado a uma vontade de superar a produção e exportação de commodities por uma estrutura industrial, que renda produtos tecnológicos de valor agregado. Estes temas, quando comparados como o modus operandi dos pressupostos religiosos pentecostais no Brasil, promovem a constação de que o modelo clericalista de domínio masculino dos postos de comando e a rejeição a modernização social, enquanto elemento de generação moral, dão a tônica desta religiosidade. Esta se aproveita da divisão sexista do poder e também da inovação, dentro daquilo que cabe a reprodução das condições tradicionais de dominação já elencadas.

Do lado dos religiosos, temos a força construtora simbólica de suas representações judaico cristãs, que mediante as ideias de regeneração, justificação, escolha e salvação eternas, propusseram em conjunto, um modelo ético de santidade que visa duas questões: fomentar um modelo cultural e estético próprio e um mercado de bens de salvação e materiais que retroalimenta a mística religiosa e o contato com Deus.

Além disso, para os pentecostais, Deus teria escolhido um povo (os Isrealitas), mediante uma promessa de preservar esta nação contra a sua destruição, fato descrito no Segundo Livro de Samuel (3:27). Porém, após a morte de Cristo e a negação dos judeus quanto ao messias enviado, o raio da escolha divina se amplia para um alcance mundial. Isso muda a noção de envangelismo e admite a posibilidade de expansão religiosa via conversão de quantos quiserem aceitar os pressupostos da fé cristã, como filhos de um único Deus sem distinção. Nisto residiria a relação de igualdade cristã. Contudo, conforme já citamos no texto, o ideal de igualdade ficaria restrito apenas a este quesito, sofrendo sérias interferências dos pressupostos doutrinários e das diferentes formas de leitura da própria Bíblia9.

Para os pentecostais assembleianos, que no Brasil representam 32\% dos protestantes e $18 \%$ do total geral de pessoas filiadas a alguma religião (DATAFOLHA, 2017), a igualdade cristã quando ampliada a outras denominações religiosas, pressupõe a afirmação de que cada interpretação teria o seu valor. Isso incorre em um erro categórico, na medida em que as

\footnotetext{
9 Há uma rejeição de campo entre os Assembleianos para com as igrejas protestantes históricas e os neopentecostais. A acusação dada aos primeiros é de que, rejeitando o uso atual dos dons espirituais, ficariam por isso, defasados em relação às potencialidades de evangelização e missão. Quanto aos neopentecostais, sua rejeição repousa na acusação de uso indevido dos dons, como meio de manipulação e fortalecimento econômico, incorrendo em venda deliberada de serviços eclesiásticos e uso de objetos mágicos.
} 
disputas dentro do campo religioso brasileiro e consequentemente, de espaço de divulgação e possibilidade de renda e poder, evidenciam um clima de concorrência sob qual denominação teria mais legitimidade.

Dito isto, consideramos que na religião a questão da liberdade pode ser colocada como elemento homogeneizante, mas tendo neste caso a visão dos propósitos utilitários. Já no quesito igualdade, as elites religiosas pentecostais assembleianas, apoiadas por uma força doutrinária e simbólica, não permitem um conciliação de interesses. Esta mesma conciliação de interesses religiosos diferenciados só é tolerada em situações de ação contra um inimigo comum: seja ele o comunismo, o relativismo cultural, as demandas das minorias, etc, buscando defender aquilo que entitulam como sendo a defesa da liberdade democrática, algo permitido aos vários grupos (religiosos ou não), enquanto direito ao exercício de suas crenças e opiniões. Disso resulta, de um lado, uma luta ferrenha entre religiosos e secularistas e de outro entre estes mesmos religiosos internamente, promovendo também possibilidades de consenso em torno do ataque direto a temas como: modelos de família não tradicionais, aborto e tributação as igrejas.

É uma mistura então de disputas por espaços sociais e rentablidades econômicas, travestidas de pressupostos de fé e defesa de uma liberdade de culto que promove desenvolvimento social. Portanto, a liberdade enquanto elemento homogeneizante é alvo de uma defesa incontéstavel por parte da elite assembleiana e sua membresia, mas é lida como direito que deveria ser regido por uma ética própria, ou seja, a ética religiosa. Tudo o que transpassar a ideia de um culto a um único Deus e encarado como transgressão moral. Por isso a sua ideia de liberdade é também uma forma de permitir a sua própria ação dentro de pressupostos culturais que são por si tolerados, mas não aceitos.

Assim o pentecostalismo alimenta a ideia de que sua missão de conversão dos pecadores é algo intrínseco à missão das igrejas no mundo. A liberdade, por sua vez, é algo que também evidencia a transgressão moral religiosa, gerando oportunidades de proselitismo. Não há espaço para o véu de ignorância de Rawls e nem para o modelo alternativo de democracia liberal de reconhecimento mútuo de Taylor. O que resta são possibilidades juridico políticas, arbitrando a todo tempo uma disputa que hora avança em termos secularizantes (legalização de crime de homofobia; tentativa de legalização do aborto), por um lado (inserção do ensino religoso no meio público, manutenção de políticas públicas com viés religioso) de outro.

Desde de que foi fundado em 1911, o modelo pentecostal assembleiano sempre teve de lidar com as pressões políticas externas, principalmente no que se refere à resistência Último Andar, n. 34, 2019 
dentro da primeira república (1989-1930). No Estado Novo, sob forte influência integralista, foi um modelo religioso que mediante as diretrizes conservadoras soube lidar com a exaltação aos símbolos nacionais e mesclou esta prática a exaltação dos símbolos religiosos. Contudo, quando ameaçada em suas crenças pelo polulismo das décadas de 1950 e 1960, soube de maneira direta se alinhar com grupos protestantes históricos e católicos em defesa da familia, do Estado e da propriedade, perfazendo um caminho de censura aos ideiais progressistas da esquerda e aos próprios membros, se alinhando de maneira direta ao regime militar. Por isso, a presença do Marechal Henrique Lott na Convenção de 1958, em Natal-RN (DANIEL, 2004).

Mas isso escondia uma questão elementar: até meados de 1980, a política assembleiana quanto à igualdade e à liberdade, estava restrita à formação de seus próprios quadros de liderança interna, que se enrijecera culturalmente no tempo. O trabalho foi de alicerce de uma unidade convencional que permitisse o fortalecimento dos "caciques regionais", isso trabalhado em quase 50 anos de funcionamento, promovendo o fortacelecimento dos postos chave e seu controle. Desta forma, foi construído da década de 1930 a 1980, um regime que sairia de sua condição intramuros para se evidenciar aos poucos mediante o espaço político nacional. Agora se tratara não de politica de aliança ao Estado para ter como resultado a proteção institucional, mediante o sentimento de subalternidade. Era a emergência de um modelo de intervenção no Estado mediante a eleição democrática de representantes internos as igrejas, para que fosse feito uma política, não para a igreja, mas da igreja.

A questão é que os pressupostos de diferenciação pela fé e ataque aos direitos via liberdade de culto e atuação política, começam a incomodar os adeptos dos direitos coletivos e democráticos de forma a colocar os pentecostais assembleianos sob a linha de frente de uma política conservadora. O que occorre é que a diferenciação entre direitos coletivos e direitos individuais não é feita de maneira coerente. Quando um político afirma que o Estado é oficialmente laico, mas sua crença pessoal e eminentemente cristã, apenas usa de uma afirmação que é conforme os principios liberais de caráter individual. Contudo, para que este mesmo Estado de moldes liberais consiga realizar uma política eminentemente pública, não deve ter como pressuposto a conformidade: há pressupotos pessoais e doutrinários, mas em pressupostos políticos de respeito à coisa pública e atendimento a demandas múltiplas e comunitárias.

\section{Considerações finais}

Último Andar, n. 34, 2019 
A complicada tarefa de conciliação entre as questões da liberdade, da igualdade e da pluralidade tem dentro do liberalismo político uma importância singular, como foi possível ver através das teorizações de John Rawls e Charles Taylor. Contudo, seu equacionamento não depente, como vimos, de uma capacidade de teorização que possa encaminhar o debate em torno de principios éticos, morais e até mesmo da defesa de pressupostos universais encarados como direitos.

Para além disso, as pessoas interessadas no jogo político, se posicionam como agentes institucionais e movem suas capacidades de influência e decisão para proposicões que, encaram o escopo das liberdades e da igualdade de maneiras distintas, dependendo dos pressupostos políticos e religiosos que estão embuidas em suas análises. Neste sentido, a restrição da liberdade diante das proposições cristãs, evidencia um pressuposto de igualdade mediante a mesma fé e a negação da pluralidade enquanto desvirtuamento relativista, dificultando o diálogo sobreposto as diferenças e também invibializando o uso do véu de ignorância de Rawls e do reconhecimento alheio de Taylor.

Resta então o arbítrio do Estado, por meio da judicialização dos direitos e inauguração de um novo campo de disputas, que mesclam os campos jurídico, social e religioso. Enquanto isso, as disparidades sociais e as diferenças culturais se acentuam, em um ritmo de polarização que cria um vazio de poder (GRAMSCI, 1968), capaz de dar voz a movimentos políticos que preencham a média das consciências conservadoras, daquilo que gostam de ouvir, promovendo neste mesmo espaço deixado, formas de intolerância travestidas de normalidade (DURKHEIM, 2019).

\section{Referências bibliográficas:}

ALENCAR, Gedeon. Assembleias brasileiras de Deus: teorização, história e tipologia 1911 2011. Tese de Doutorado defendida na Pontificia Universidade Católica de São Paulo - PUCSP, 2012.

ARISTÓTELES. A política. 2a edição. São Paulo: EDIPRO, 2009.

BÍBLIA DE JERUSALÉM. Bíblia Sagrada. São Paulo: Paulus, 1994.

BOURDIEU, Pierre; PASSERON, Jean-Claude. A reprodução: elementos para uma teoria do sistema de ensino. $7^{\text {a }}$ edição. Petrópolis: Vozes, 2011. 
CARNEIRO, Carlos David. Justiça política entre a igualdade e a diferença: explorando a política do reconhecimento de Charles Taylor. Revista da Facultade de Diretiro-RFD-UERJ. Rio de Janeiro, n. 28, dez. 2015.

DANIEL, Silas. História da Convenção Geral das Assembleias de Deus no Brasil. Rio de Janeiro: CPAD, 2004.

DURKHEIM, Émile. As regras do método sociológico. Petrópolis: Vozes, 2019.

EHRENBERG, Alain. O culto da performance: da aventura empreendedora e depressão nervorsa. São Paulo: Idéias e Letras, 2010.

FROSI, Julio Cesar. A autonomia privada na liberdade religiosa com ênfase na teoria da justiça de John Rawls. Revista da Unioesc, 2014.

GRAMSCI, Antônio. Maquiavel, a política e o Estado moderno. Tradução de Luiz Mário Gazzaneo. Rio de Janeiro: Civilização Brasileira, 1968.

KANT, Immanuel. Crítica da Razão Pura. Petrópolis: Vozes, 2015.

LOCKE, John. Dois tratados sobre o governo civil. Lisboa: Edições 70, 2006.

MARIZ, Cecilia Loreto. Secularização e dessecularização: comentários a um texto de Peter Berger. Religião e Sociedade. Rio de Janeiro. v. 21, 2001, p. 25-40.

MARSHALL, Thomas Humphrey. Cidadania e Classe Social. $2^{\mathrm{a}}$ edição. Brasília: Senado Federal, 2002.

MONTERO, Paula. Religiões e controvérsias públicas: experiências, práticas sociais e discursos. São Paulo: Editora terceiro nome, 2015.

PESQUISA DATAFOLHA, 2017. 44\% dos evangélicos são ex-católicos. Dispónivel em: http://datafolha.folha.uol.com.br/opiniaopublica/2016/12/1845231-44-dos-evangelicos-saoex-catolicos.shtml. Acesso em: 28/12/2016.

PIPER, John. Cinco Pontos: em direção a uma experiência mais profunda da graça de Deus. São Paulo: FIEL, 2018.

RAWLS, John. Uma teoria da justiça. São Paulo: Martins Fontes: 2016.

SAHLINS, Marshall. Ihas de História. Rio de Janeiro: Zahar, 1990.

SCHUMPETER, Joseph A. Capitalismo, Socialismo e Democracia. São Paulo: UNESP, 2017.

SWEDBERG, Richard. Max Weber e a ideia de Sociologia Econômica. Rio de Janeiro: Editor UFRJ, 2005.

TAYLOR, Charles. Politics of Recognition. In: GUTMANN, Amy (org). Multiculturalism: Examining the Politics of Recognition. Princeton: Princeton University Press, 1994. 
WEBER, Max. A ética protestante e o espírito do capitalismo. São Paulo: Companhia das Letras, 2004.

Ciência e Política: duas vocações. 12a edição. São Paulo: Cultrix, 2011.

WEFFORT, Francisco (Org.). Clássicos da Política. Vol. 1. São Paulo: Ática, 2006.

Submetido em 01/09/2019

Aprovado em 05/12/2019 